\title{
Correspondence
}

\section{Pathogenesis of cupping of the optic disc} TO THE EDITOR British Fournal of Ophthalmology

SIR, Professor Hayreh has performed a great service in reiterating the ischaemic nature of optic disc cupping and of the particular susceptibility of the prelaminar tissue and peripapillary choroid to imbalance between the intraocular pressure and local perfusion pressure (Hayreh, 1974a). I would disagree with him, however, that the atrophic cupping seen after temporal arteritis is 'identical in all aspects' to that seen in glaucoma and low-tension glaucoma. Since the occurrence of cupping in temporal arteritis was first brought to my notice at the Oxford Congress in 1972 (Miller, 1972) I have been looking at my cases for this and have, indeed, found cupping not infrequently. I assume that Professor Hayreh is referring to the clinical appearance of the discs and not to other clinical details such as the complete loss of vision or gross altitudinal loss in the one compared to the usual presence of good vision, apart from typical scotomata, in the other. No one is likely to confuse them clinically and it may be on this account, as well as its rather tardy development in many cases, that its occurrence in temporal arteritis has previously been practically overlooked. But there are some differences in ophthalmoscopic appearance, especially before the intraocular pressure has been normalized. The glaucomatous cup is of a darker grey especially where it

\section{Pathogenesis of cupping of the optic disc} TO THE EDITOR British Yournal of Ophthalmology

SIR, I should like to thank Mr John Primrose for confirming the occurrence of cupping of the optic disc in temporal arteritis, not only found by me but also reported by Mr S. J. H. Miller in his Doyne Memorial Lecture at the Oxford Congress in 1972. However, I disagree with $\mathrm{Mr}$ Primrose in his other statements. The clinical ophthalmoscopic appearance of the optic disc cupping seen in temporal arteritis is very similar to that seen in chronic simple glaucoma and low-tension glaucoma with cupping usually maximal in the temporal part of the optic disc and with nasal displacement of the main retinal vessels. This is evident from Fig. 2d (Hayreh, 1974) and Mr Miller agreed with me in the observation. I feel the degree of greyness mentioned by Mr Primrose is irrelevant and of no practical significance because there is a considerable variation in the greyness seen in different discs in both glaucoma and temporal arteritis. He has made no mention of the exact incidence of 'darker grey', or 'paler grey' (both of which descriptions are subjective) or of the absence of greyness in optic disc cupping in glaucoma and, it seems, that he has made his statement purely on so-called 'clinical impressions' derived from routine ophthalmoscopy which a scientific study might reveal to be without statistical significance. In my studies I personally photographed on Kodachrome II colour films with a stereoscopic fundus camera the optic discs of every patient with temporal arteritis, and my observations were based on stereoscopic examination of these discs at a standard illumination; this method provides a considerable amount of information which is not usually obtained reaches to the edge of the disc, which it usually does only in parts (above and below), except in cases where it is very advanced and there are other signs such as displacement of vessels against the nasal wall of the cup. In early cases there may also be fullness of veins. The cupping I have seen in temporal arteritis, and only in about half of my cases, is of a paler grey, reaching the edge all round unless a sector of field is spared without any particular displacement of vessels, and with a general attenuation of vessels. It is what is called 'atrophic cupping' and this is a useful term to distinguish it from glaucomatous cupping.

I had hoped Hayreh, 1974b, might elucidate these points, and also that the paper would give the incidence of cupping. However, the table and figure were the same in both papers, and one cannot elucidate the incidence as there were 13 eyes, some bilateral, out of 25 cases. Please could he put the record straight.

Regional Eye Centre, Yours faithfully, Oldchurch Hospital, JOHN PRIMROSE Romford, Essex

References

HAYREH, S. S. (1974a) Brit. F. Ophthal., 58, 863 (1974b) Ibid., 58, 964

MILLER, S. J. H. (1972) Trans. ophthal. Soc. U.K., 92, 563

by routine ophthalmoscopy with variable illumination.

I feel Mr Primrose's concept of 'atrophic cupping' is not what is classically known in ophthalmology. As is well known, this is seen in marked optic atrophy and consists of a very shallow saucer-shaped or flat depression (not a cup) involving the optic disc, without any steep edges or nasal displacement of the main retinal vessels. Histopathologically, in 'atrophic cupping' there is a destruction of nerve fibres only, without any loss of glial cells; whereas in glaucomatous cupping (and also in temporal arteritis) there is ischaemic destruction of both the nerve fibres and the glial cells in the prelaminar part of the disc. Thus to describe cupping of the optic disc in temporal arteritis as 'atrophic cupping' would not only be erroneous but also misleading.

I have given the incidence of optic disc cupping in the table mentioned by Mr Primrose. The incidence pertains to the number of eyes in my series and not the cases; I feel the latter is irrelevant as we are interested in finding the incidence of the cupping in the eyes affected by temporal arteritis and not in the cases, since every patient with temporal arteritis does not have both eyes involved and sometimes no ocular involvement at all. Thus any mention of incidence of cupping of the disc in patients would be misleading.

The University of Iowa

Yours faithfully, SOHAN S. HAYREH Department Ophthalmology,

Iowa City,

Iowa, USA

Reference

HAYREH, s. S. (1974) Brit. F. Ophthal., 58, 968 